\title{
DESIGN AND VERIFICATION OF A NEW ENERGY SAVING ELECTRIC EXCAVATOR
}

\author{
Kyoung Kwan $\mathrm{Ahn}^{1} *$, Jong Il Yoon ${ }^{2}$, and Dinh Quang Truong ${ }^{1}$ \\ ${ }^{1}$ School of Mechanical and Automotive Engineering, University of Ulsan, Ulsan, Korea \\ ${ }^{2}$ Graduated School of Mechanical and Automotive Engineering, University of Ulsan, Ulsan, Korea \\ *Corresponding author (kkahn@ulsan.ac.kr)
}

\begin{abstract}
The aim of this paper is to propose a new type of excavator - electric excavator (ELEX) - with energy saving capacity using six quasi independent electro-hydraulic actuators (EHAs). The quasi-independent configuration minimizes hydraulic interferences among the actuators and losses which occur in traditional hydraulic excavators (HYEXs). In addition, the boom/arm/or bucket cylinder is driven by a closed EHA system, so that potential energy accumulated at "up" positions can be recuperated and converted into electricity via the EHA generator when the boom/arm/or bucket goes down, respectively. Kinetic energy of the upper slewing body also can be recovered and converted into electricity when a slewing stop happens. A 5-ton excavator using a hybrid boom system (HBS) was analyzed, developed as an experimental ELEX (EELEX) for evaluating the proposed ELEX. A control strategy for the 5-ton EELEX was built to operate the machine to follow desired performances. Higher working efficiency and less energy consumption of the EELEX have been clearly verified through simulations and experiments in comparison with the conventional 5-ton HYEX.
\end{abstract}

Keywords: Hydraulic Excavator, Electric Excavator, Electro-Hydraulic Actuator, Control, Saving Energy

\section{INTRODUCTION}

Hydraulic systems are indispensable components of many modern work machines. Excavators are subjected to large variations in workloads while repeating high work load operations, such as excavation, and low work load operations, such as leveling. In a conventional HYEX, hydraulic power, corresponding to the maximum workload, is always supplied from a pump and excessive power is dissipated as heat. In addition, potential and kinetic energies at the times of lowering and slewing stoppage of the excavator are also dissipated as heat. Hence, reductions of energy consumption and pollution become necessary and urgent demands. And hybrid electro-hydraulic vehicles, especially hybrid construction machines, are feasible solutions [1-3]. However, performances of these machines in comparison with corresponding conventional machines have been not much considered.

This paper proposes one effective solution for excavator design - electric excavator using EHAs. In this ELEX, it is recognized that the EHAs consume less energy than conventional hydraulic valve-controlled actuators. In addition the potential energy derived from gravity of the EHAs with/without working loads during their operations may be stored and later returned to the system as needed. A 5-ton experimental excavator with a modification - hybrid boom system was then implemented for validating the performance of the proposed ELEX. Based on the EELEX structure and working conditions, a control strategy was designed to control the HBS with high working efficiency and energy saving capacity. Simulations and practical experiments have been then carried out to investigate the efficiency of the proposed EELEX machine.

\section{ELECTRIC EXCAVATOR (ELEX) DESIGN}

\subsection{ELEX design concept}

Configuration of the suggested electric excavator is suggested as shown in Fig. 1. The ELEX comprises six quasi independent EHAs [4] driven by electric motor/generators and pumps which represent for the swing, left traveling, right traveling, boom, arm and bucket system. 


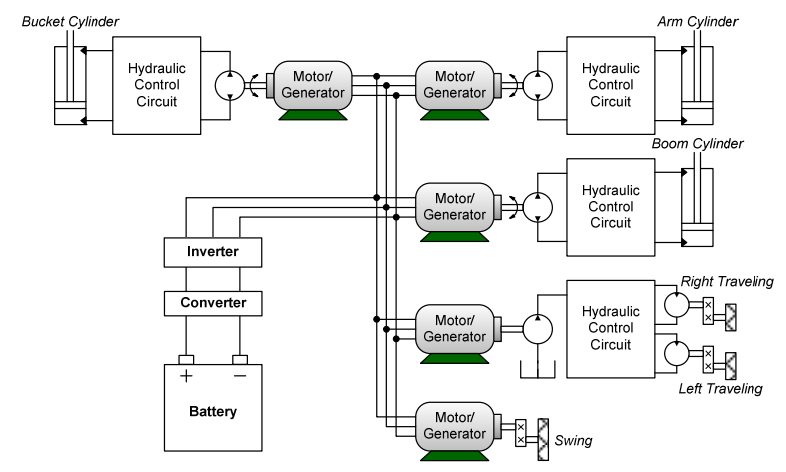

Fig. 1 Proposed electric excavator configuration

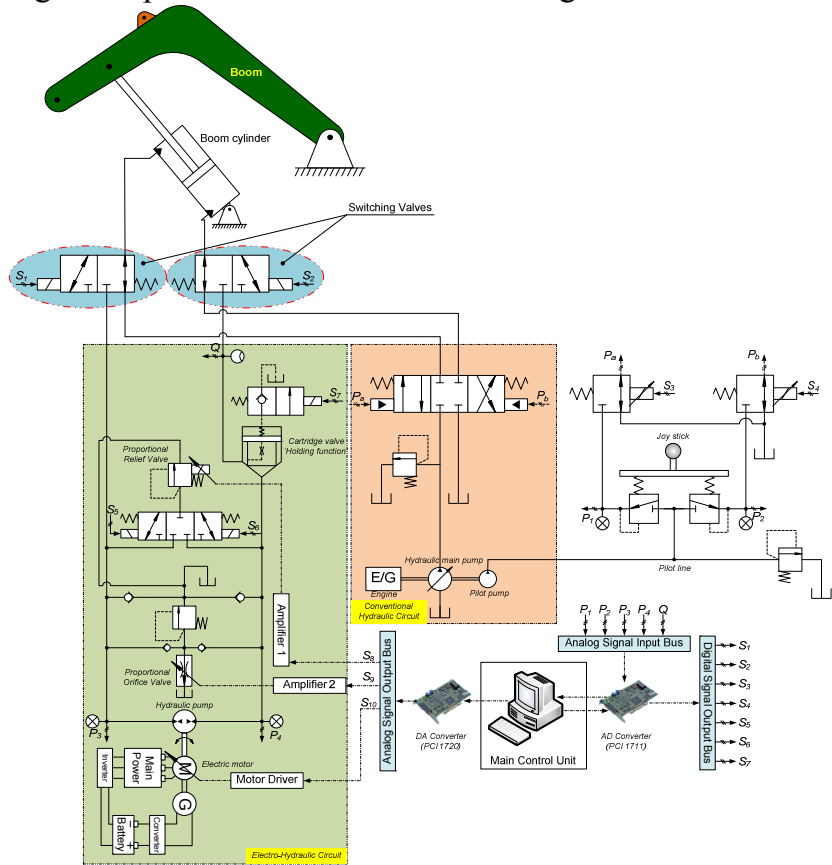

Fig. 2 Integrated control circuit for HBS and CBS

Therefore, the quasi-independent configuration of the ELEX minimizes hydraulic interferences among the actuators and losses which occur in conventional excavators [4]. With the suggested excavator design, the boom/arm/or bucket cylinder is driven by a closed system comprising an EHA, so that potential energy accumulated at "up" positions can be recuperated and converted into electric energy via the hydraulic motor and the generator when the boom/arm/or bucket goes down, respectively. The slewing motions are driven by an electric motor, instead of a hydraulic actuator. Consequently, kinetic energy of the upper slewing body can be recovered and converted into electric energy when a slewing stop happens. Power source of the ELEX is an external battery and capacitors inside motor drivers of the EHAs. To realize the energy saving capacity of the excavator, the internal capacitors stores the electric power generated by the potential energy or kinetic energy. The battery is automatically recharged when the amount of generated electric energy is more than the capacity of the capacitors.

\subsection{Experimental electric excavator (EELEX)}

To verify the effectiveness of the ELEX design idea suggested in the previous section, the 5 ton experimental electric excavator was analyzed and re-fabricated from a 5ton hydraulic excavator. Here, the EELEX is a combination of the HYEX using a conventional boom system (CBS) and a hybrid boom system (HBS). The integrated HBSCBS circuit is depicted in Fig. 2.

In this figure, the HBS is depicted as the 'green' block. The boom cylinder can be driven in both directions by the electric motor/generator combined with the bi-directional hydraulic pump/motor and the hydraulic control circuit. In this circuit, a $3 / 3$ solenoid valve with a proportional pressure relief valve were installed to distribute flow lines. In addition, a proportional orifice valve was employed in the HBS to adjust the boom down speed. In order to make the load holding function for the boom cylinder, an orifice cartridge valve was used and connected between the port of the cylinder large chamber and one port of the pump/motor. The combined HBS-CBS circuit was designed to be controlled with a user-interface program from a PC. It helps the user can easily switch the excavator from using the CBS to using the HBS and vice versa by using two solenoid 3/2 switching valves $\left(S_{I}\right.$ and $\left.S_{2}\right)$. The excavator works as the HYEX when these valves are OFF. On the contrary, the excavator works with the hybrid boom system. Based on the circuits proposed in Fig. 2, components needed to construct the system were chosen to satisfy the working requirements of the EELEX. Subsequently, the specifications and setting parameters for the integrated HBS-CBS boom system are listed in Table 1.

\section{CONTROL STRATEGY FOR BOOM SYSTEM}

\subsection{Working principle}

\subsubsection{Conventional boom system}

In case of 'Boom Up' mode, the signal $P_{2}$ is high pressure (at that time, $P_{l}=0$ ) and sent to the control line $P_{b}$ on the right hand side of the $4 / 3$ main control valve. As a result, 
hydraulic oil is pumped from the main pump system to the boom cylinder large chamber to cause it to extend.

On the other hand, with a rising pressure of $P_{l}$ (at that time, $P_{2}=0$ ), the main supply oil line is connected with the cylinder small chamber, consequently, causing the cylinder to retract. It is called 'Boom Down' mode of the CBS.

\subsubsection{Hybrid boom system}

The HBS operation is divided into four modes: 'Boom Up', 'Boom Slow Down', 'Boom Fast Down', 'Digging' mode.

a) Mode 1 - 'Boom Up'mode

In this mode, the electric motor/generator works as an electric motor while the hydraulic pump/motor functions as a bi-directional hydraulic pump. The motor generates the speed and torque for the hydraulic pump in the direction to supply the high pressure oil $\left(P_{4}\right)$ into the cylinder large chamber. The motor speed affects directly the cylinder moving speed. The pump inlet flow with low pressure $\left(P_{3}\right)$ is from the low pressure lines connected from the cylinder small chamber and the tank. The orifice cartridge with the holding function only allows the flow to get into the cylinder large chamber which causes the boom to move up.

\section{b) Mode 2 - 'Boom Slow Down'mode}

Here, the electric motor/generator functions as an electric generator while the hydraulic pump/motor becomes a hydraulic motor. Because of gravity of the boom with or without load, the boom is automatically lowered, consequently, converting the potential energy generated during the 'Boom Up' mode into mechanical energy by the hydraulic motor. The mechanical power is then converted into electric energy and stored in the battery by the generator. In order to increase the energy saving capacity in this mode, the line connected from the hydraulic motor to the cylinder small chamber needs to be a low pressure line $\left(P_{3}\right)$ as the tank with atmospheric pressure. Hence, setting pressure of the proportional relief valve is set to zero while the orifice of the flow control valve is closed. The generated electric power $\left(P_{\text {gen }}\right)$ can be calculated as

$P_{\text {gen }}=U_{\text {gen }} \times I_{\text {gen }}=P_{\text {pot }}-P_{\text {lost }}[\mathrm{W}]$

where: $U_{\text {gen }}[V]$ and $I_{\text {gen }}[A]$ are generated voltage and generated current, respectively; $P_{p o t}$ and $P_{\text {lost }}$ are in turn potential power and lost power.

c) Mode 3 - 'Boom Fast Down' mode

Contrary to mode 2, in this case the electric motor/generator works as the electric motor while the hydraulic pump/motor works as the hydraulic pump when the boom cylinder is commanded to retract fast. The piston is retracted by both the potential energy and power supplied from the motor which runs in the direction to lower the boom. Therefore, the hydraulic line from the cylinder large chamber to the pump is a low pressure line $\left(P_{4}\right)$ while the line connecting between the cylinder small chamber and the pump has high pressure $\left(P_{3}\right)$. Moreover, control signals are sent to the proportional relief valve and the flow control valve to set the relief pressure and the

Table 1. Specifications and setting parameters of the modified boom system

\begin{tabular}{|c|c|c|c|}
\hline \multicolumn{2}{|c|}{ Modified Boom System } & Parameters & Values \\
\hline \multirow{3}{*}{ Common Parts } & \multirow{3}{*}{$\begin{array}{l}\text { Boom } \\
\text { Cylinder }\end{array}$} & Piston diameter $(\mathrm{mm})$ & 110 \\
\hline & & Rod diameter $(\mathrm{mm})$ & 60 \\
\hline & & Length of stroke $(\mathrm{m})$ & 0.72 \\
\hline \multirow{5}{*}{$\begin{array}{c}\text { Conventional Boom } \\
\text { System }\end{array}$} & Engine & Speed (rpm) & 2300 \\
\hline & Main pump & Variable displacement (cc/rev) & $16+2 \times 25$ \\
\hline & Servo pump & Fixed displacement (cc/rev) & 4.5 \\
\hline & Control Valve & Ports/Positions (Hydraulic control) & $4 / 3$ \\
\hline & Relief valve & Relief pressure (bar) & 210 \\
\hline \multirow{8}{*}{ Hybrid Boom System } & \multirow{3}{*}{$\begin{array}{l}\text { Brushless servo motor } \\
\text { (MPP2308P) }\end{array}$} & Input voltage (VAC) & 400 \\
\hline & & Rated speed (rpm) & 1805 \\
\hline & & Rated torque $(\mathrm{Nm})$ & 73.757 \\
\hline & Breaking resistor & Resistance $(\mathrm{Ohm})$ & 27 \\
\hline & Bi-directional & Displacement (cc/rev) & 45 \\
\hline & Relief valve & Relief pressure (bar) & 320 \\
\hline & Proportional Relief valve & Relief pressure (bar) & $0 \sim 315$ \\
\hline & Proportional & Percentage of maximum & $0 \sim 100$ \\
\hline \multirow{3}{*}{$\begin{array}{l}\text { Main Control Unit } \\
\text { (MCU) }\end{array}$} & $\mathrm{PC}$ & Intel Core ${ }^{\mathrm{TM}} 2$ duo & $2.4 \mathrm{GHz}$ \\
\hline & PCI 1711 & Advantech multifunction card & $\mathrm{A} / \mathrm{D}$ \\
\hline & PCI 1720 & Advantech multifunction card & $\mathrm{D} / \mathrm{A}$ \\
\hline
\end{tabular}


orifice area, respectively, proportional to the given joystick command. The input power $\left(P_{m}\right)$ for the electric motor to cause the boom to lower is taken from the main power supply and the potential energy as

$P_{m}=T_{m} \times \omega_{m}=P_{\text {elec }}^{*}+P_{p o t}^{*}-P_{\text {lost }}^{*}[\mathrm{~W}]$

where: $T_{m}, \omega_{m}$ are torque, angular velocity of the electric motor; $P_{\text {elec, }}, P_{\text {pot }}^{*}$ and $P_{\text {lost }}^{*}$ are electric power supply, potential power and lost power in mode 3 , respectively.

d) Mode 4 - 'Digging'mode

In this mode, the electric motor generates the torque and speed for the pump to supply high pressure oil $\left(P_{3}\right)$ to the small chamber of the boom cylinder (as in mode 3). An electric control signal $\left(S_{6}\right)$ is sent to the solenoid on the right hand side of the control valve which is opposite energizing side when compared to the energizing side of the control valve in the modes from 1 to 3 . The return line from the cylinder large chamber to the pump inlet port is then connected to the tank through the proportional relief valve with a small setting pressure and it becomes a low pressure line. Therefore, the different volume between fluid in the large chamber and in the small chamber is returned to the tank to make a balance of fluid lines.

To make the HBS to be automatically switched between its operating modes to satisfy the driver commands, a control strategy was necessary and designed as presented in Fig. 3.

\subsection{Motor speed control}

In order to ensure that the motor as well as the boom cylinder can follow the desired speed, an auto-adjustable proportional-integral-derivative (PID) controller, was applied to control the motor speed. The control signal for the electric motor $\left(u_{P I D}(t)\right)$ can be then expressed as:

$u_{P I D}(t)=K_{p} e(t)+K_{i} \int_{0}^{t} e(t) d t+K_{d} \frac{d e(t)}{d t}$

where: $e(t)$ : the error between the desired speed and current speed, $d e(t)$ : the derivation of error; $K_{p}, K_{i}$, and $K_{d}$ : the proportional, integral, and derivative gains, respectively. To make the controller more adaptive, the PID gains need to be switched corresponding to the working conditions. Hence, a switching algorithm using a learning vector quantization neural network (LVQNN) was proposed and designed in this paper. The LVQNN was constructed by a hidden competitive layer and a linear output layer. The
LVQNN estimates the PID gains based on the current working mode of the boom which are determined by the pressure sensor signals from the joystick $\left(P_{1}, P_{2}\right)$ and from the HBS circuit $\left(P_{3}, P_{4}\right)$. The detailed design process as well as training process of the switching algorithm was referred from the previous research [5]. As a result, the control scheme for the motor speed tracking task is depicted in Fig. 4.

For each of the HBS working mode, a set of the PID gains, $K_{p}, K_{i}$, and $K_{d}$, was derived by 'trials and errors' method with respect to reduce the control error. Consequently, the gain sets corresponding to the HBS working modes were found as given in a look-up table - Table 2 .

Table 2. Look-up table for tuning the PID gains

\begin{tabular}{|c|c|c|c|}
\hline HSB modes & $K_{p}$ & $K_{i}$ & $K_{d}$ \\
\hline Boom Up & 100 & 0.1 & 0.01 \\
\hline Boom Slow & 10 & 0.1 & 0 \\
\hline Boom Fast Down & 100 & 0.1 & 0.01 \\
\hline Digging & 100 & 0.1 & 0 \\
\hline
\end{tabular}

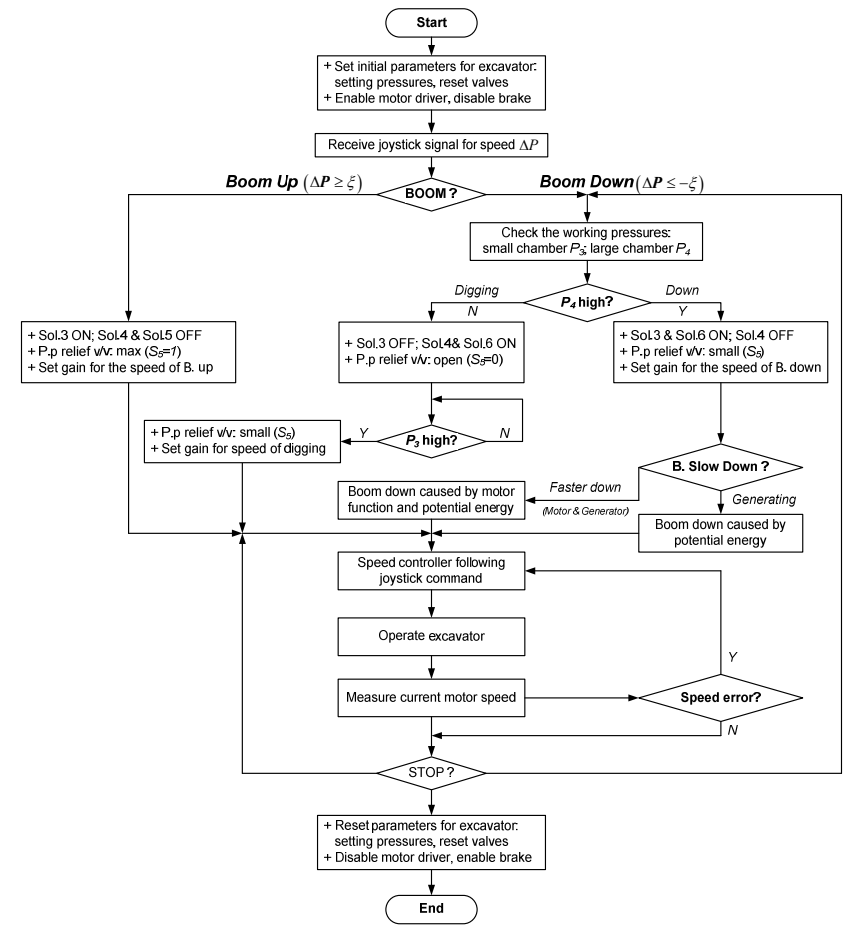

Fig. 3 Overview of control strategy applied to the EELEX

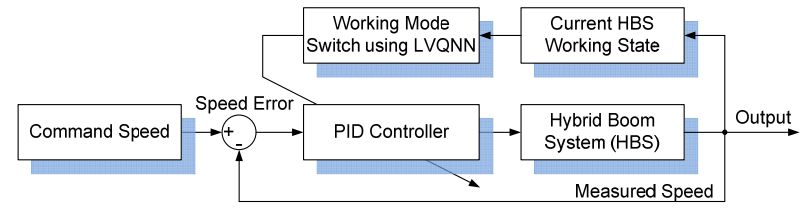

Fig. 4 Overview of the auto-adjustable PID controller for speed control of the EELEX 


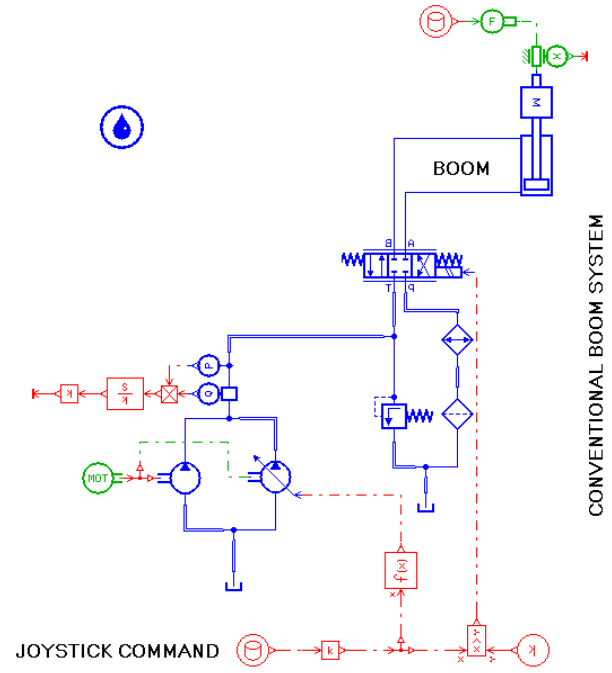

Fig. 5-a AMESim model for the conventional boom system

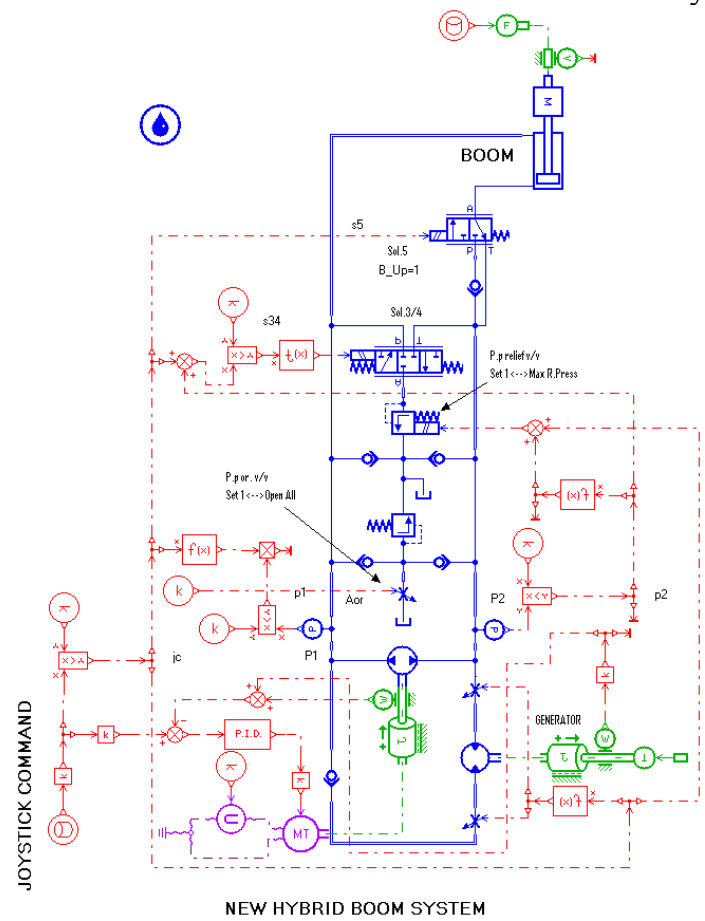

Fig. 5-b AMESim model for the hybrid boom system

\section{SIMULATIONS}

In order to verify working efficiency of the proposed excavator, two models representing for the CBS and HBS circuits have been built using AMESim software version 4.3.0 as shown in Fig. 5a and 5b, respectively. The setting parameters for these models were obtained from the information of the real boom systems in Table 1 .

The input parameters for the boom models were joystick command and loading force attached to the piston rod. The input data was obtained from a real experiment done by a well-working driver on the 5-tons excavator for only boom up and down process in several times with maximum moving speed and without working load at the bucket. Simulations were then performed with this input data. To investigate the effect of using the flow control valve in the HBS, the HBS model has been tested with two cases: without and with using the flow control valve.

The reduction in energy consumption of the HBS when compared with that of the CBS can be computed as

$$
\begin{aligned}
& \text { \%SavedEnergy }=\frac{\left(\sum E_{\text {used }}\right)_{C B S}-\left(\sum E_{\text {used }}\right)_{H B S}}{\left(\sum E_{\text {used }}\right)_{C B S}} \times 100 \% \\
& =\frac{\left[\left(\sum E_{\text {used }}\right)_{C B S}-\left(E_{\text {supplied }}-E_{\text {generated }}\right)_{H B S}\right]}{\left(\sum E_{\text {used }}\right)_{C B S}} \times 100 \% \\
& \left(\sum E_{\text {used }}\right)_{C B S}=\int_{0}^{t_{\text {frinsh }}}\left(T_{m 1}+T_{m 2}\right) \omega_{m} d t \\
& \left(\sum E_{\text {used }}\right)_{H B S}=\int_{0}^{t_{\text {frusish }}} U_{\text {supplied }} I_{\text {supplied }} d t \\
& \left(\sum E_{\text {generated }}\right)_{H B S}=\int_{0}^{t_{\text {frinish }}} T_{\text {generated }} \omega_{\text {generated }} d t
\end{aligned}
$$

here: $t_{\text {finish }}$ : simulating time; $T_{m 1}$ and $T_{m 2}$ : torques generated by the CBS fixed and variable pumps; $U_{\text {supplied, }} I_{\text {supplied }}$ : supplied voltage and current from the main electric power; $T_{\text {generated }}, \omega_{\text {generated }}$ : generated torque and angular velocity.

The simulated performances of the CBS and HBS were obtained and analyzed as in Table 3. As seen in this table, the simulated energy consumption of the HBS model without using the flow control valve was reduced by $55.14 \%$ comparing with that of the CBS model. Meanwhile, by using the flow control valve in the HBS, the simulated energy consumption was significantly reduced up to $75.12 \%$. It proves clearly that the high working efficiency could be realized in the proposed HBS, especially in case of using the flow control valve. In addition, the HBS had the ability in saving energy as depicted in Table 3.

\section{EXPERIMENTS}

To investigate the ability of the proposed ELEX in the real working environment, experiments with the 5-tons EELEX were carried out. The control strategy introduced in Section 3 was built within Simulink environment combined with Real-time Windows Target Toolbox of MATLAB. Here, the power supplied to the HBS was electric power while the power supplied to the CBS was gasoline fuel. 
Experiments have been carried out for the EELEX with fast full up and down strokes of the boom (without working load) in two cases: using the CBS and the HBS. The reduction in energy consumption of the EELEX using the HBS when compared with using the CBS is obtained by (4) in which the total energy used in each the system can be calculated as (8), (6) and (9).

$$
\begin{aligned}
& \left(\sum E_{\text {used }}\right)_{C B S}=\left(\sum \text { GasolineFuel }_{\text {used }}\right)_{C B S} \\
& \left(\sum E_{\text {generated }}\right)_{H B S}=\int_{0}^{t_{\text {frimsh }}} R_{\text {breaking }}\left(I_{\text {generated }}\right)^{2} d t
\end{aligned}
$$

here: $R_{\text {breaking }}$ is the beaking resistor (Table 1), and $I_{\text {generated }}$ is the generated current.

Finally, the boom working performances were analyzed through the experiment results as given in Table 4. From this table, it clearly shows that the high working efficiency could be enhanced in case the EELEX using the HBS. Here, the recuperated energy from the boom potential energy was $0.734 \mathrm{~kJ}$. This generated energy is small because the EELEX is 5-tons type in which the boom weight was small and the excavator was tested without working load. The more working load, the bigger potential energy as well as recuperated energy could be obtained. Moreover, the experiments with the boom down and fast moving speed caused the HBS to operate mostly in 'Boom Fast Down' mode in which the generated energy is un-considered.

\section{CONCLUSIONS}

This paper presents the new idea design of ELEX using EHAs. The 5-tons excavator was re-assembled with the HBS in order to improve the working efficiency. In addition, the proper control strategy was designed to manage the operation of the experimental electric excavator with the high working performance.

Table 3. Simulation results - Energy consumption analysis

\begin{tabular}{|c|r|r|r|r|}
\hline \multirow{2}{*}{ Simulation cases } & \multicolumn{4}{|c|}{ Energy analysis for the boom models with up-down motion } \\
\cline { 2 - 5 } & Total supplied & Generated energy & Total energy & \multicolumn{1}{c|}{ Saved } \\
\hline CBS & 669.2 & 0 & 669.2 & 0 \\
\hline HBS without flow control valve & 304.7 & 4.453 & 300.247 & 55.14 \\
\hline HBS with flow control valve & 167.6 & 1.099 & 166.501 & 75.12 \\
\hline
\end{tabular}

Table 4. Real time testing results - Working performance analysis

\begin{tabular}{|c|r|r|r|r|r|}
\hline \multirow{2}{*}{$\begin{array}{c}\text { Test case: } \\
\text { Boom Fast Up-Fast Down Motions }\end{array}$} & \multicolumn{4}{|c|}{ Comparison factors for one cycle time $T$ of boom system operation } \\
\cline { 2 - 6 } & Cycle Time & Total supplied & Generated & \multicolumn{1}{c|}{ Total used } & \multicolumn{1}{c|}{ Saved } \\
\hline CBS & 5.625 & 78.136 & 0 & 78.136 & 0 \\
\hline HBS & 7.375 & 41.539 & 0.734 & 40.809 & 47.772 \\
\hline
\end{tabular}

The AMESim models have been built to verify the designed hybrid circuit and the control strategy. The simulations and experiments have been done to evaluate the ability of the suggested boom system. The results prove that the boom cylinder controlled by the HBS circuit could reduce remarkably energy consumption when compared with the boom cylinder controlled by the traditional circuit. This proposed ELEX can become an optimal selection for the heavy industry in a near future with energy saving and green emission purpose.

\section{ACKNOWLEDGEMENTS}

This work was supported by Brain Korea 21 (BK21).

\section{REFERENCES}

[1] Ochiai, M., "chnical Trend and Problem in Construction Machinery", Construction Machinery, Vol. 38(4), pp. 20-24, 2002.

[2] Xiao, Q., Wang, Q., and Zhang, Y., "Control strategies of power system in hybrid hydraulic excavator", Automation in Construction, Vol. 17(4), pp. 361-367, 2008.

[3] Lin, X., Pan, S.X., and Wang, D.Y., "Dynamic simulation and optimal control strategy for a parallel hybrid hydraulic excavator", J. of Zhejiang University Science A, Vol. 9(5), pp. 624-632, 2008.

[4] Truong, D.Q. and Ahn, K.K., "Force control for hydraulic load simulator using self-tuning grey predictor - fuzzy PID”, Mechatronics, Vol. 19(2), pp. 233-246, 2009.

[5] Ahn K.K, Chau N.H.T, "Intelligent switching control of a pneumatic muscle robot arm sing learning vector quantization neural network", Mechatronics, Vol. 17(45), pp. 255-262, 2007. 